Scientific Review - Engineering and Environmental Sciences (2021), 30 (3), 439-450

Sci. Rev. Eng. Env. Sci. (2021), 30 (3)

Przegląd Naukowy - Inżynieria i Kształtowanie Środowiska (2021), 30 (3), 439-450

Prz. Nauk. Inż. Kszt. Środ. (2021), 30 (3)

http://iks.pn.sggw.pl

DOI 10.22630/PNIKS.2021.30.3.37

Haider M. Al-JELAWY ${ }^{1}$, Ayad Al-RUMAITHI ${ }^{2}$, Aqeel T. FADHIL ${ }^{2}$, Alaa J. NAJI ${ }^{1}$

${ }^{1}$ University of Al-Qadisiyah, College of Engineering

${ }^{2}$ University of Baghdad, College of Engineering

\title{
Mesoscale modeling of fracture in cement and asphalt concrete
}

Key words: mesoscale model, damage model, fracture energy, cement concrete, asphalt concrete, disk-shaped compact tension test

\section{Introduction}

Numerical modeling of concrete materials has taken several paths over the years. The most common method is macroscale modeling where concrete is modeled as a homogenous material. This type of modeling has two distinct approaches: continuum models and fiber-based models. Continuum models are the most commonly used type which utilize commercial finite element programs and they are computationally expensive. Fiber-based models, on the other hand, are less common and not computationally costly (Al-Jelawy, 2017; Haber, Mackie \& Al-Jelawy, 2017; Al-Jelawy, Mackie \& Haber, 2018). Recently, an- other type of modeling has emerged which is the mesoscale modeling.

Mesoscale modeling has become an alternative modeling method for macroscale modeling for the simulation of heterogeneous materials such as cement and asphalt concrete since realistic damage prediction and crack growth are crucial aspects of such materials (Unger, Eckardt \& Kooenke, 2011; Thilakarathna, Baduge, Mendis, Vimonsatit \& Lee, 2020). Mesoscale modeling in cement or asphalt concrete requires aggregate and mortar to be modeled as separate constituents. Sometimes an interfacial transition zone (ITZ) between the aggregate and mortar is modeled as a third material (Unger \& Eckardt, 2011).

Heterogeneous material is created using image processing techniques or through random generation of aggregates. Aggregate can be rounded in shape or having sharp angles. Aggregate 
size distribution is modeled through prescribed curves or empirical equations such as Fuller curve (Häfner, Eckardt, Luther \& Kőnke, 2006; Zhang, Song, Liu, Wu \& Song, 2017). Material models are then assigned to the aggregate and mortar based on their individual properties.

In previous studies, continuum models such as smeared crack models, damage models, and plastic-damage models were used to represent fracture properties within the numerical model (Unger \& Eckardt, 2011). Also, models which utilized discrete cracks implemented in rigid-body-spring model were used (Grassl \& Bažant, 2009), or discrete cracks which were included in finite elements such as extended finite elements (Moës, Dolbow \& Belytschko, 1999).

Recently, the use of mesoscale modeling has been limited to simulate specimen subject to tension (Kim \& Al-Rub, 2011; Unger \& Eckardt, 2011; Unger et al., 2011; Chen, Xu, Mo \& Zhou, 2018; Zhou \& Lu, 2018; Karavelić, Nikolić, Ibrahimbegovic \& Kurtović, 2019; Jin, Yu, Du \& Yang, 2020) and compression (Xie, Guo, Yuan \& Huang, 2015; Chen et al., 2018; Zhou \& Lu, 2018; Karavelić et al., 2019; Chen et al., 2020). The use of fracture mechanics in civil engineering have restraints related to the selection of the test specimen geometry and the available equipment to run the test. The common specimen geometry used for concrete fracture testing is the three-point notched beam. Specimens extracted from the field have become more desirable in order to evaluate in situ structure capacity. Therefore, concrete cores are a suitable option for fracture testing since extracting beams from the field is difficult. Recently, geometry selection for concrete (Amirkhanian, Spring, Roesler \& Paulino, 2016) was motivated by previous research on asphalt concrete specimens (Wagnoner, Buttlar \& Paulino, 2005; Wagnoner, Buttlar, Paulino \& Blankenship, 2006; Kim, Buttlar, Baek \& Al-Qadi, 2009) where a disk-shaped compact tension test (DCT) was used extensively on asphalt core specimens that gave consistent and accurate results. Later the DCT geometry was adopted for asphalt specimens as a standard in ASTM D7313 (ASTM International [ASTM], 2013). The main advantage of the DCT specimen geometry is the easy fabrication from a field core or laboratory cylinder. Numerical studies that are performed on cement and asphalt DCT tests are mainly in macroscale (Wagnoner et al., 2005; Amirkhanian et al., 2016). Only one mesoscale study was conducted on mesoscale asphalt concrete specimens (Kim et al., 2009), while none were implemented on cement concrete DCT tests.

The objective of this study is to perform a mesoscale analysis on DCT specimens of cement concrete and asphalt concrete in order to obtain more realistic behavior of these heterogeneous materials. In mesoscale models, aggregate and matrix are represented as distinct materials and each material has its characteristic properties. Experimental data from previous studies on DCT specimens were used to validate the modeling results in terms of load-crack mouth opening displacement (CMOD) relationship. 


\section{Material models}

Material models for fracture mechanics are mainly two types: constitutive models that represent cracks as a reduction in constitutive stiffness such as smeared crack model, damage models and damage-plasticity models. The other type of models such as embedded finite elements (Jirásek, 2000) and extended finite elements (Moës et al., 1999) utilizes a crack as a discontinuity in the displacement field. The first type of models has gained popularity due to its compatibility with finite element analysis (Rots, Nauta, Kuster Blaauwendraad, 1985; Rots, 1988; Rots \& Blaauwendraad, 1989).

In the current study, isotropic damage model was used, and it is explained in the subsequent paragraphs. The softening curve for this model is defined as a function of fracture mechanics parameters.

This is the simplest form of damage models. It assumes that the damage is equal in all directions and represented by scalar value - $\omega$ (Kachanov, 1986; Lemaitre \& Chaboche, 1990). The model is applied to the cementitious material only (such as cement mortar or asphalt) while the aggregate is modeled using its elastic properties.

The damage model is based on the following stress-strain relationship:

$$
\sigma=(1-\omega(\epsilon)) D_{\varepsilon}
$$

where $D$ is the elastic material matrix. The damage $(\omega)$ can be defined as a function of fracture mechanics parameters as (Kurumatani, Terada, Kato, Kyoya \& Kashiyama, 2016):

$$
\omega(\epsilon)=\left\{\begin{array}{l}
1-\frac{1}{E}\left(\frac{1}{\epsilon} \cdot\left(f_{t}-\left(f_{t}-\sigma_{s}\right) \cdot \frac{\left(\epsilon-\epsilon_{0}\right)}{w_{s}}\right)\right), \\
\text { if }\left(\epsilon-\epsilon_{0}\right)<w_{s} \\
1-\frac{1}{E}\left(\frac{1}{\epsilon} \cdot\left(\sigma_{s} \cdot\left(w_{c}-\frac{\left(\epsilon-\epsilon_{0}\right)}{w_{c}-w_{s}}\right)\right)\right), \\
\text { if }\left(\epsilon-\epsilon_{0}\right) \geq w_{s} \text { and }\left(\epsilon-\epsilon_{0}\right)<w_{c} \\
1, \quad\left(\epsilon-\epsilon_{0}\right) \geq w_{c}
\end{array}\right.
$$

Equation (2) is for bilinear softening, other softening types have different equations. The damage $(\omega)$ is zero if $\epsilon<\epsilon_{0}$.

Where:

$E$ - elastic modulus of the concrete or asphalt mortar material,

$f_{t}$ - uniaxial tensile strength of the concrete or asphalt mortar material,

$\sigma_{s}-$ stress at the point of slope change of bilinear softening curve, $\sigma_{s}=$ $=0.25 f_{t}$,

$w_{s}$ - damage at the point of slope change of bilinear softening curve, $w_{s}=0.15 w_{c}$.

$w_{c}$ - damage occurs at critical crack width. It can be defined as:

$w_{c}=5 \frac{G_{f}}{h f_{t}}$

Where $G_{f}$ is the total fracture energy of the mortar material and $h$ is equivalent element size defined as: 
$h=\sqrt{A_{e}}$

for quadratic elements and:

$$
h=\sqrt{2 A_{e}}
$$

for triangular element where $A_{e}$ is the element area. $\epsilon_{0}$ is the cracking strain and defined as:

$\epsilon=\frac{f_{t}}{E}$

$\epsilon$ is the highest equivalent strain the material ever experienced and related to equivalent strain $\varepsilon_{e q}$ in case of loading and unloading as:

$\varepsilon_{e q}>\epsilon \Rightarrow \epsilon=\varepsilon_{e q}$ (loading)

$\varepsilon_{e q} \leq \epsilon \Rightarrow \epsilon=\epsilon$ (unloading)

Equivalent strain is defined as:

$\varepsilon_{e q}=\sqrt{\varepsilon_{1 b}^{2}+\varepsilon_{2 b}^{2}}$

Where:

$\varepsilon_{1 b}=\varepsilon_{1}$ if $\varepsilon_{1}>0$ otherwise $\varepsilon_{1 b}=0$

$\varepsilon_{2 b}=\varepsilon_{2}$ if $\varepsilon_{2}>0$ otherwise $\varepsilon_{2 b}=0$ (11)

Where $\varepsilon_{1}$ and $\varepsilon_{2}$ are major and minor principal strains. It has been shown that isotropic damage model has low mesh sensitivity than other models such as smeared crack models (Kurumatani et al., 2016).

\section{Geometry generation}

To obtain a realistic representation of the concrete structure, the shape and size distribution of aggregate are described using a grading curve. Grading curves can be obtained using empirical equations such as Fuller curve. In the current study, Fuller curve was used which is in the following form:

$$
\text { passing }=\left(\frac{d}{d_{\max }}\right)^{\alpha} \cdot 100
$$

where

$d \quad-$ sieve size [mm],

$d_{\max }-$ maximum size of aggregate [mm],

passing - accumulated percentage that pass the sieve size [\%],

$\alpha-$ Fuller curve exponent and assumed to equals to 0.45 in the current study. Figure 1a shows an example of actual and simulated aggregate distribution using Fuller curve.

After that, ellipsoids are generated in three-dimensional domain (refer to Fig. 1b). Each individual ellipsoid has dimensions which are determined from the sieve curve and aspect ratio of the required aggregate. Aggregates are placed according to algorithm commonly known as set and place method which is explained by Unger et al. (2011). Based on this algorithm, the particles are divided into sets based on their sizes and then placed individually. If the placed particle intersects with another particle it will be placed again in a different empty spot. After particle placement was done, the ellipsoids were cut by a plane to obtain ellipses to shift the focus on two dimensional problems (refer to Fig. 1c). The cutting plane is located in the middle of width direction to avoid underrepresentation of larger particles near the edges of the specimen. Afterwards, specimen was 
a

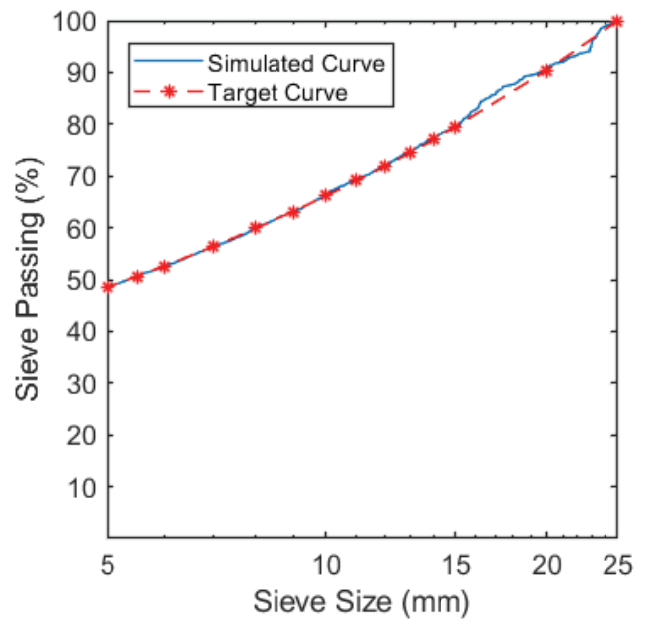

c

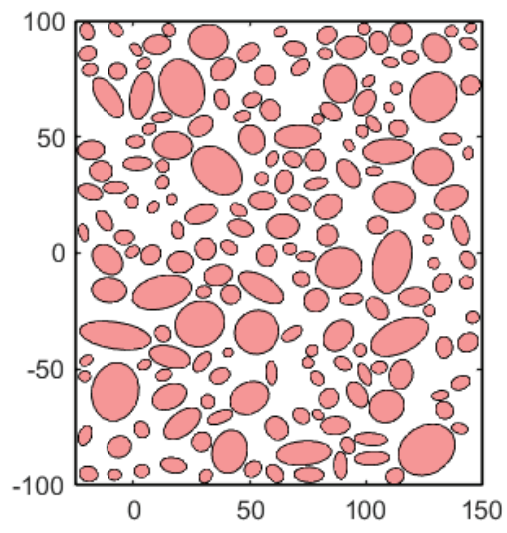

b

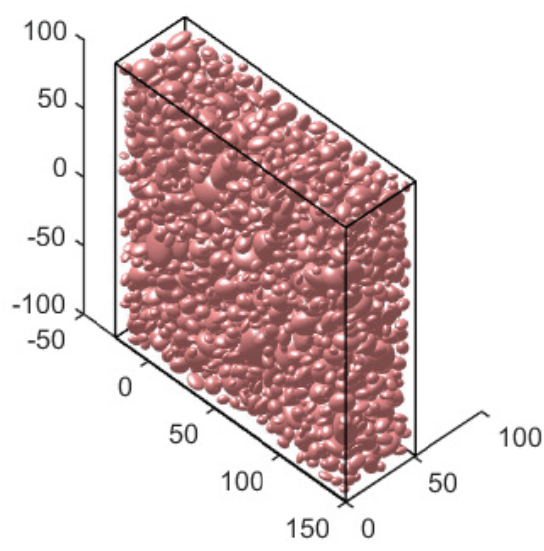

d

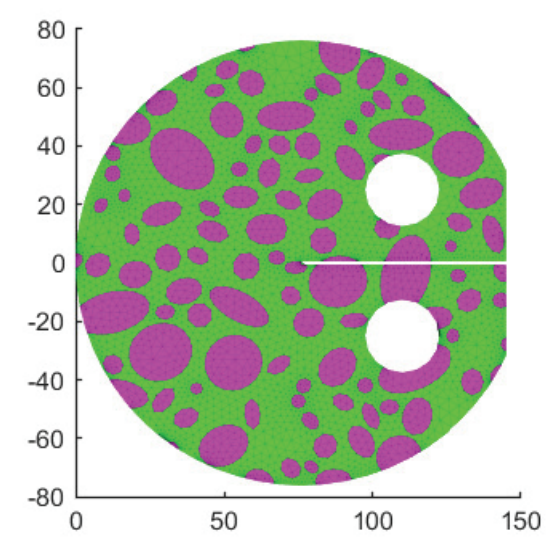

FIGURE 1. Geometry generation steps: a - sieve analysis; b - ellipsoids; $\mathrm{c}$ - ellipses; $\mathrm{d}$ - mesh

cut to form a disk-shaped geometry similar to that used in DCT test and a notch was made (see Fig. 1d). The ellipses were allowed to be cut at the boundaries to simulate in-situ conditions. Triangular mesh based on Delaunay triangulation was generated using MESH2D MATLAB code for two-dimensional geometries (Engwirda, 2005, 2014).

\section{Numerical solution method}

Cement and asphalt concrete tests were simulated using finite element method, and the triangular mesh was modeled as constant strain triangles elements. The applied load was vertical static support displacement through the circular holes with additional horizon- 
tal support to ensure translational and rotation stability. The non-linear behavior was solved using Newton Raphson method with line searches implemented in MATLAB. The analysis results were compared with available experimental data in subsequent sections.

\section{Model validation with Portland cement concrete experiments}

The numerical model was validated against experimental tests of disk-shaped tension tests of concrete specimens. The selected specimens were tested by Amirkhanian et al. (2016). The material average properties are given in Table 1 . They were 24 cored specimens, 18 specimens were tested at age 710 days (referred to as Mortar 1 in Table 1) and 6 specimens were tested at 1,578 days (Mortar 2 in Table 1). The averaged curves of the two types of the specimens were used in the comparisons with the numerical model.
Limestone coarse aggregate was used in all specimens with grading size of 5-20 $\mathrm{mm}$. The percentage of coarse and fine aggregate was assumed $75 \%$ by volume. Fuller curve exponent of 0.45 was adopted. Aggregate distribution for the two types of specimens (Mortar 1 and Mortar 2) is shown in Figure 2a and Figure 3a, respectively. Disk geometry for the two types of specimens is shown in Figure $2 b$ and Figure $4 b$, respectively. Crack growth from numerical simulation is shown in Figure $2 \mathrm{c}$ and Figure $3 \mathrm{c}$ for the two types. It can be observed that crack initiation and propagation are more realistic than straight cracks in macroscale models. The relationship between load and CMOD for the two types of specimens from numerical analysis is comparable to that from the experiments as depicted in Figure $2 \mathrm{~d}$ and Figure $3 \mathrm{~d}$, respectively. The numerical model is able to predict the tensile strength, initial stiffness and the softening branch of load-CMOD curve with good accuracy.

TABLE 1. Material properties for cement concrete specimen

\begin{tabular}{|l|c|c|c|c|}
\hline \multirow{2}{*}{ Aggregate } & $E[\mathrm{MPa}]$ & $v$ & $f_{t}[\mathrm{MPa}]$ & $G_{f}\left[\mathrm{~N} \cdot \mathrm{mm}^{-1}\right]$ \\
\cline { 2 - 5 } & 45000 & 0.2 & - & - \\
\hline Mortar 1 & $38000^{*}$ & 0.2 & $4^{* *}$ & $0.15^{* *}$ \\
\hline Mortar 2 & $38000^{*}$ & 0.2 & $4.62^{* * *}$ & $0.163^{* * *}$ \\
\hline
\end{tabular}

* Mortar modulus of elasticity was chosen in order to achieve bulk modulus of elasticity 40,600 MPa by using the following equation based on Reuss formula (Reuss, 1929):

$$
E_{\text {bulk }}=\frac{100}{\frac{\% \text { aggregate }}{E \text { aggregate }}+\frac{\% \text { mortar }}{E \text { mortar }}}
$$

**Tensile strength in macroscale model was $4 \mathrm{MPa}$ and fracture energy is $0.1252 \mathrm{MPa}$.

***Tensile strength in macroscale model was 4.2 MPa and fracture energy is 0.148 MPa. 
a

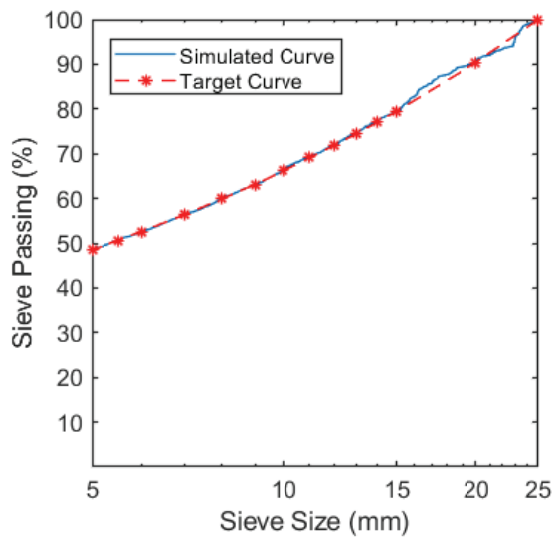

c

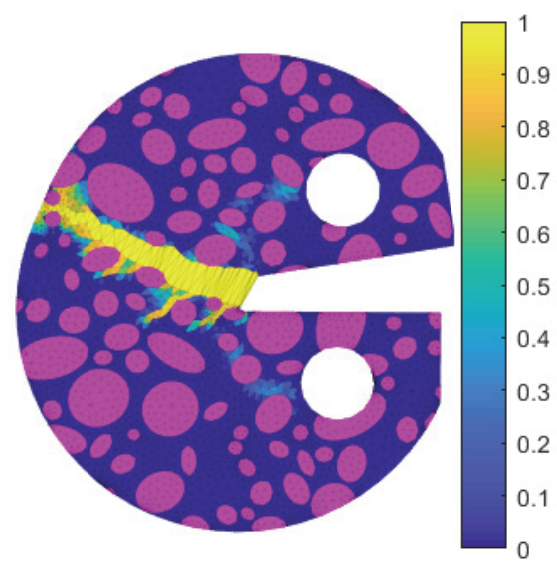

b

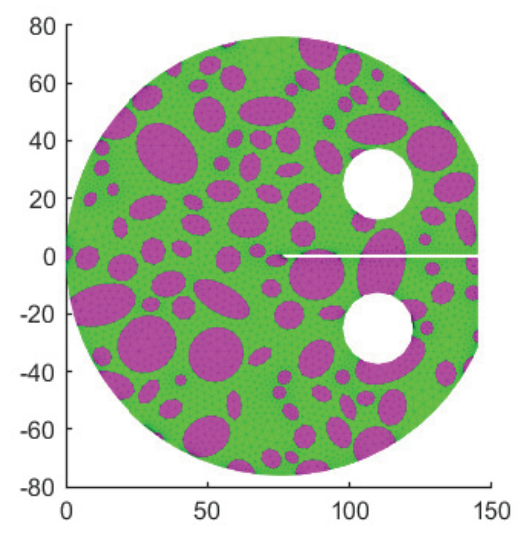

d

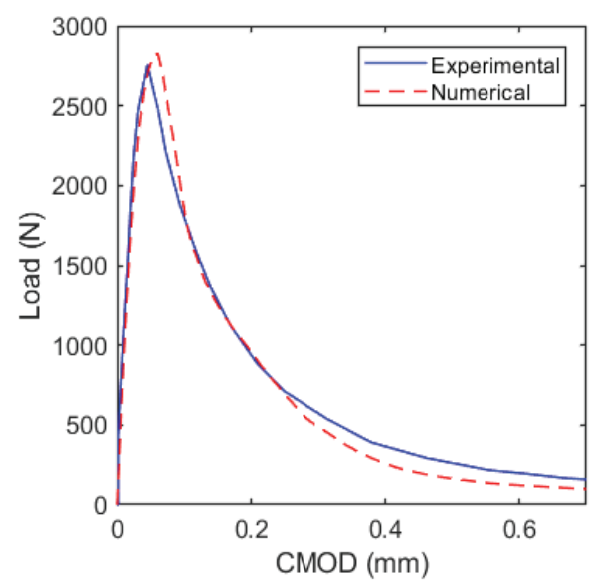

FIGURE 2. Model validation for cement concrete DCT (Mortar 1) specimens: $a-$ sieve analysis; $b$ cement concrete mesh (7,028 elements); $\mathrm{c}$ - crack path at failure; $\mathrm{d}$ - load-CMOD curves 
a

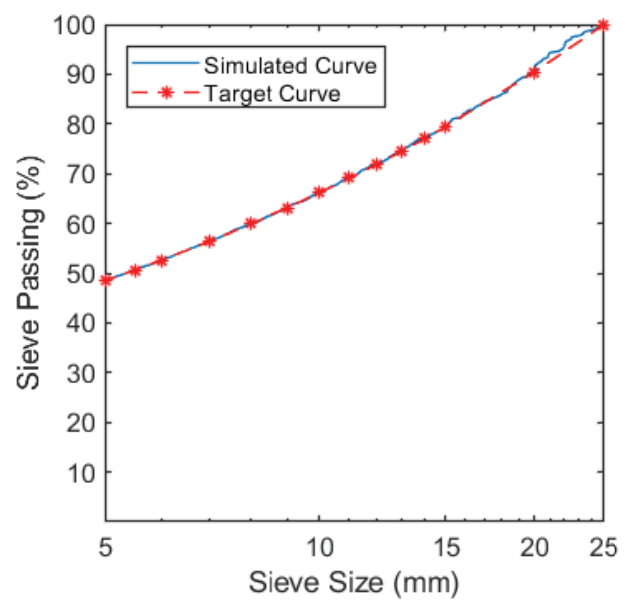

C

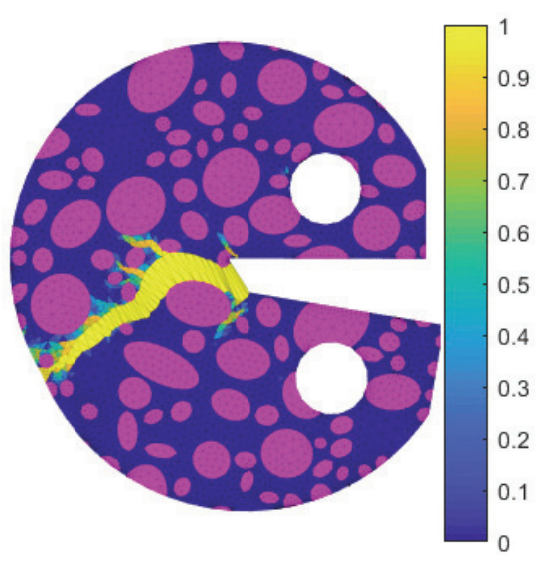

b

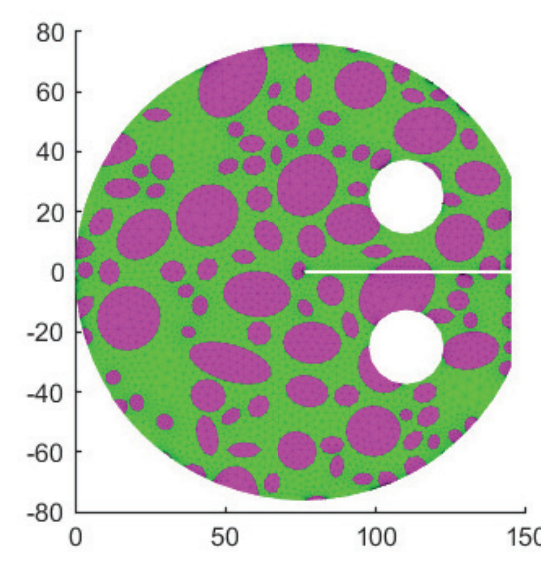

d

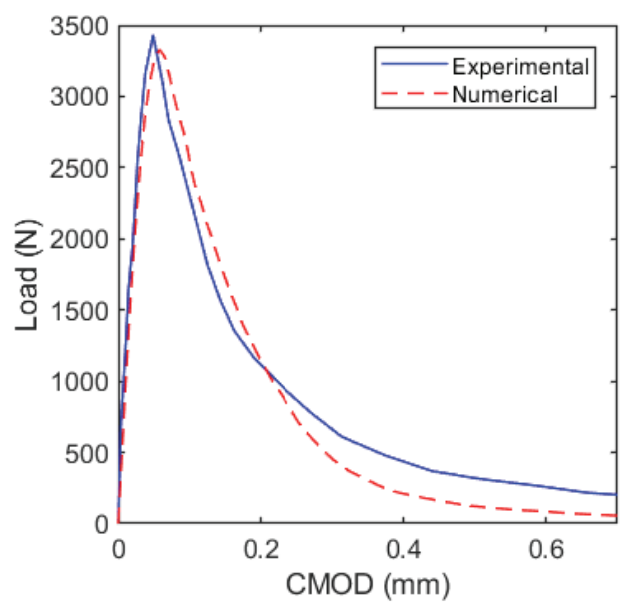

FIGURE 3. Model validation for cement concrete DCT (Mortar 2) specimens: a - sieve analysis; $\mathrm{b}$ - cement concrete mesh (8,082 elements); $\mathrm{c}$ - crack path at failure; $\mathrm{d}$ - load-CMOD curves

\section{Comparisons with asphalt concrete experiments}

In addition to the concrete specimens, of disk-shaped tension tests of asphalt specimens were used to validate the proposed numerical model. Three specimens were tested by Wagnoner et al. (2005). One mix was used with aggregate of grading size of $5-9.5 \mathrm{~mm}$ and an asphalt binder. Percentage of aggregate was assumed to be $90 \%$ by volume. Fuller curve exponent of 0.45 was adopted. Aggregate distribution of the 
a

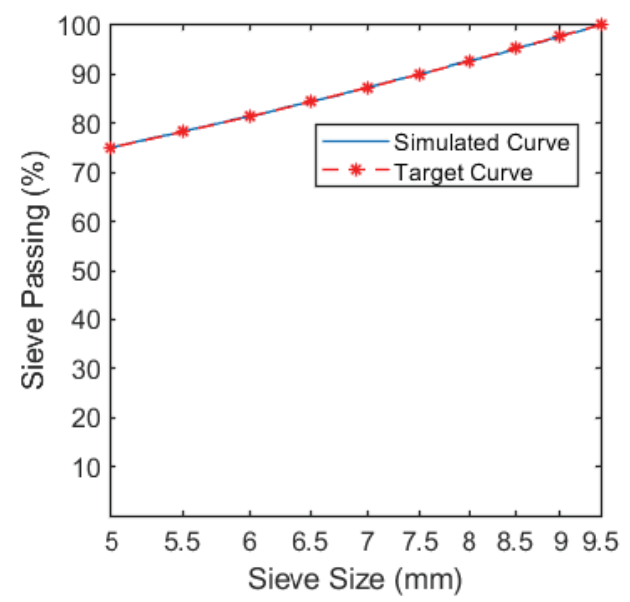

C

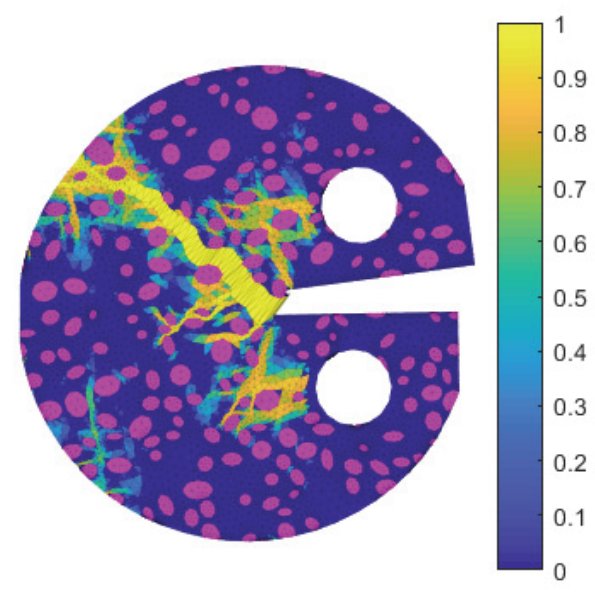

b

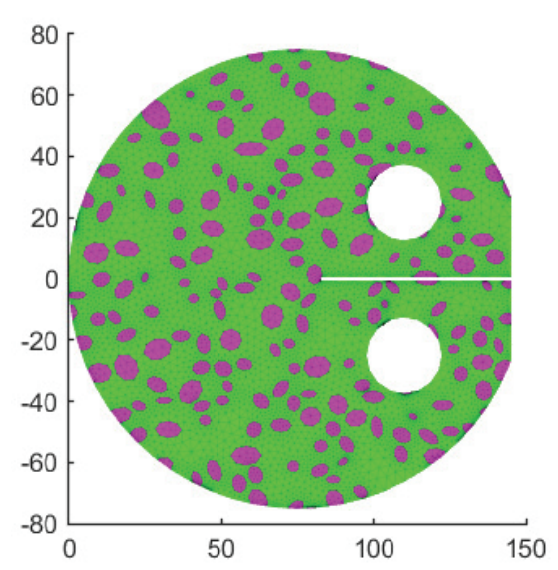

d

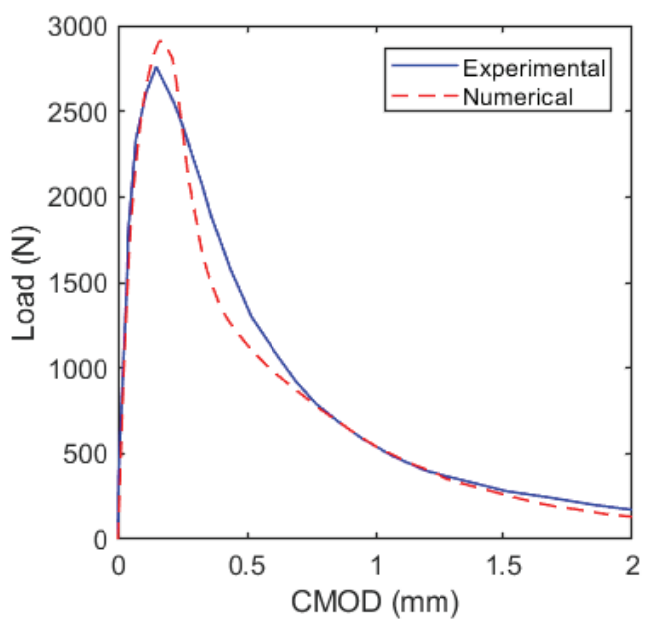

FIGURE 4. Model validation for asphalt concrete DCT specimens: $a$ - sieve analysis; $b$ - asphalt concrete mesh (14,708 elements); $\mathrm{c}$ - crack path at failure; $\mathrm{d}$ - load-CMOD curves

specimens is shown in Figure 4a. Disk geometry of specimens is shown in Figure $4 \mathrm{~b}$. The failure mode of the specimen from the numerical modeling is shown in Figure 4c. It can be seen that crack initiation and propagation are similar to that in an actual asphalt concrete specimen.
Also, the numerical load-CMOD curve is in agreement with the experimental curve as depicted in Figure 4d. The predicted tensile strength, initial stiffness and the softening branch of load-CMOD curve are comparable to the experimental results. 
TABLE 2. Material properties for asphalt concrete specimen

\begin{tabular}{|l|c|c|c|c|}
\hline Material & $E[\mathrm{MPa}]$ & $v$ & $f_{t}[\mathrm{MPa}]$ & $G_{f}\left[\mathrm{~N} \cdot \mathrm{mm}^{-1}\right]$ \\
\hline Aggregate & 50000 & 0.2 & - & - \\
\hline Mastic & $12000^{*}$ & 0.35 & $2.85^{* *}$ & $0.459^{* *}$ \\
\hline
\end{tabular}

*Mastic modulus of elasticity was chosen in order to achieve bulk modulus of elasticity $14,200 \mathrm{MPa}$ by using the following equation based on Reuss formula (Reuss, 1929):

$$
E_{\text {bulk }}=\frac{100}{\frac{\% \text { aggregate }}{E \text { aggregate }}+\frac{\% \text { mastic }}{E \text { mastic }}}
$$

**Tensile strength chosen $80 \%$ of indirect tensile splitting test results, while in the macroscale model of the original paper it was $74 \%$. Fracture energy value in macroscale model is 0.328 .

\section{Conclusions}

In this study, mesoscale modeling is performed on fracture behavior of cement and asphalt concrete composites using disk-shaped compact tension (DCT) tests. Realistic behavior of composite and heterogeneous materials such as cement and asphalt concrete require mesoscale modeling. In the presented model, aggregate and matrix (cement mortar or asphalt) are represented as distinct materials and each material has its characteristic properties where the matrix is modeled using isotropic damage model with softening and the aggregate is modeled using its elastic properties. Diskshaped compact tension test is a better alternative to other tests such as three points bending tests for the determination of tensile strength and fracture energy of materials because it is more convenient for both field and laboratory specimens in addition to its accurate results. The test geometry is generated using a MATLAB code that takes care of the shape and size distribution of the aggregate. The numerical results show that the predicted load-CMOD curves are in good agreement with the experimental curves for both cement and asphalt concrete. Also, the numerical model can capture the variability of crack direction very well.

\section{References}

Al-Jelawy, H. (2017). Shifted plastic hinge column connections using grouted sleeves for accelerated bridge construction (doctoral dissertation). University of Central Florida, Orlando (FL).

Al-Jelawy, H.M., Mackie, K.R. \& Haber, Z.B. (2018). Shifted plastic hinging for grouted sleeve column connections. ACI Structural Journal, 115(4), 1101-1114.

Amirkhanian, A.N., Spring, D.W., Roesler, J.R. \& Paulino, G.H. (2016). Forward and inverse analysis of concrete fracture using the diskshaped compact tension test. Journal of Testing and Evaluation, 44(1), 625-634.

ASTM International [ASTM] (2013). Standard method for determining fracture energy of asphalt-aggregate mixtures using the disk-shaped compact tension geometry (ASTM D7313-13). West Conshohocken (PA): ASTM International. 
Chen, H., Xu, B., Mo, Y.L. \& Zhou, T. (2018). Behavior of meso-scale heterogeneous concrete under uniaxial tensile and compressive loadings. Construction and Building Materials, 178, 418-431.

Chen, H., Xu, B., Wang, J., Zhou, T., Nie, X. \& Mo, Y.L. (2020). Parametric analysis on compressive strain rate effect of concrete using mesoscale modeling approach. Construction and Building Materials, 246, 118375. https:// doi.org/10.1016/j.conbuildmat.2020.118375

Engwirda, D. (2005). Unstructured mesh methods for the Navier-Stokes equations (undergraduate thesis). The University of Sydney, Sydney.

Engwirda, D. (2014). Locally optimal Delaunayrefinement and optimisation-based mesh generation (doctoral dissertation). The University of Sydney, Sydney.

Grassl, P. \& Bažant, Z.P. (2009). Random lattice-particle simulation of statistical size effect in quasi-brittle structures failing at crack initiation. Journal of Engineering Mechanics, 135(2), 85-92.

Haber, Z.B., Mackie, K.R. \& Al-Jelawy, H.M. (2017). Testing and analysis of precast columns with grouted sleeve connections and shifted plastic hinging. Journal of Bridge Engineering, 22(10), 04017078. https://doi.org/10.1061/(ASCE)BE.19435592.0001105

Häfner, S., Eckardt, S., Luther, T. \& Könke, C. (2006). Mesoscale modeling of concrete: geometry and numerics. Computers \& Structures, 84(7), 450-461.

Jin, L., Yu, W., Du, X. \& Yang, W. (2020). Mesoscale simulations of size effect on concrete dynamic splitting tensile strength: influence of aggregate content and maximum aggregate size. Engineering Fracture Mechanics, 230, 106979. https://doi.org/10.1016/j.engfra cmech.2020.106979

Jirásek, M. (2000). Comparative study on finite elements with embedded discontinuities. Computer Methods in Applied Mechanics and Engineering, 188(1-3), 307-330.

Kachanov, L. (1986). Introduction to continuum damage mechanics. Berlin: Springer Science $\&$ Business Media.

Karavelić, E., Nikolić, M., Ibrahimbegovic, A. \& Kurtović, A. (2019). Concrete meso-scale model with full set of 3D failure modes with random distribution of aggregate and cement phase. Part I: formulation and numerical implementation. Computer Methods in Applied Mechanics and Engineering, 344, 1051-1072.

Kim, M., Buttlar, W.G., Baek, J. \& Al-Qadi, I.L. (2009). Field and laboratory evaluation of fracture resistance of illinois hot-mix asphalt overlay mixtures. Transportation Research Record, 2127(1), 146-154.

Kim, S.M. \& Al-Rub, R.K.A. (2011). Meso-scale computational modeling of the plastic-damage response of cementitious composites. Cement and Concrete Research, 41(3), 339-358.

Kurumatani, M., Terada, K., Kato, J., Kyoya, T. \& Kashiyama, K. (2016). An isotropic damage model based on fracture mechanics for concrete. Engineering Fracture Mechanics, $155,49-66$.

Lemaitre, J. \& Chaboche, J.L. (1994). Mechanics of solid materials. Cambridge: Cambridge University Press.

Moës, N., Dolbow, J. \& Belytschko, T. (1999). A finite element method for crack growth without remeshing. International Journal for Numerical Methods in Engineering, 46(1), 131-150.

Reuss, A. (1929). Calculation of the yield point of mixed crystals. Journal of Applied Mathematics and Mechanics, 9(1), 49-58.

Rots, J.G. (1988). Computational modeling of concrete fracture. Delft: Technische Hogeschool Delft.

Rots, J.G. \& Blaauwendraad, J. (1989). Crack models for concrete, discrete or smeared? Fixed, multi-directional or rotating? HERON, 34(1), 1989.

Rots, J.G., Nauta, P., Kuster, G.M.A. \& Blaauwendraad, J. (1985). Smeared crack approach and fracture localization in concrete. HERON, 30(1), 1985.

Thilakarathna, P.S.M., Baduge, K.K., Mendis, P., Vimonsatit, V. \& Lee, H. (2020). Mesoscale modelling of concrete - a review of geometry generation, placing algorithms, constitutive relations and applications. Engineering Fracture Mechanics, 231, 106974. https://doi.org/10.1016/j.engfracm ech.2020.106974 
Unger, J.F. \& Eckardt, S. (2011). Multiscale modeling of concrete. Archives of Computational Methods in Engineering, 18(3), 341-393.

Unger, J.F., Eckardt, S. \& Kooenke, C. (2011). A mesoscale model for concrete to simulate mechanical failure. Computers \& Concrete, 8(4), 401-423.

Wagnoner, M.P., Buttlar, W. \& Paulino, G.H. (2005). Disk-shaped compact tension test for asphalt concrete fracture. Experimental Mechanics, 45(3), 270-277.

Wagnoner, M.P., Buttlar, W.G., Paulino, G.H. \& Blankenship, P. (2006). Laboratory testing suite for characterization of asphalt concrete mixtures obtained from field cores (with discussion). Journal of the Association of Asphalt Paving Technologists, 75, 815-851.

Xie, Z.H., Guo, Y.C., Yuan, Q.Z. \& Huang, P.Y. (2015). Mesoscopic numerical computation of compressive strength and damage mechanism of rubber concrete. Advances in Materials Science and Engineering, 2015, 257984. https://doi.org/10.1155/2015/279584

Zhang, Z., Song, X., Liu, Y., Wu, D. \& Song, C. (2017). Three-dimensional mesoscale modelling of concrete composites by using random walking algorithm. Composites Science and Technology, 149, 235-245.

Zhou, R. \& Lu, Y. (2018). A mesoscale interface approach to modelling fractures in concrete for material investigation. Construction and Building Materials, 165, 608-620.

\section{Summary}

Mesoscale modeling of fracture in cement and asphalt concrete. In this paper, mesoscale modeling is performed to simulate and understand fracture behavior of two concrete composites: cement and asphalt concrete using disk-shaped compact tension (DCT) tests. Mesoscale models are used as alternative to macroscale models to obtain better realistic behavior of composite and heterogeneous materials such as cement and asphalt concrete. In mesoscale models, aggregate and matrix are represented as distinct materials and each material has its character- istic properties. Disk-shaped compact tension test is used to obtain tensile strength and fracture energy of materials. This test can be used as a better alternative to other tests such as three points bending tests because it is more convenient for both field and laboratory specimens in addition to its accurate results. Comparing the numerical results of the mesoscale models of cement and asphalt concrete specimens with experimental data shows that these models can predict the behavior of these composite materials very well as seen in the curves of load-crack mouth opening displacement (CMOD). Also, the mesoscale modeling highlights the variability of crack direction where it is dependent on the random distribution of aggregate.

\section{Authors' address:}

Haider M. Al-Jelawy - corresponding author (https://orcid.org/0000-0003-2465-794X)

University of Al-Qadisiyah

College of Engineering

Roads and Transport Engineering Department

Al-Jamaah Str., Al Diwaniyah

Iraq

e-mail: haider.aljelawy@qu.edu.iq

Ayad Al-Rumaithi

University of Baghdad

College of Engineering

Department of Civil Engineering

Baghdad

Iraq

Aqeel T. Fadhil

University of Baghdad

College of Engineering

Department of Civil Engineering

Baghdad

Iraq

\section{Alaa J. Naji}

University of Al-Qadisiyah

College of Engineering

Roads and Transport Engineering Department

Diwaniyah

Iraq 